\title{
Implementation of the digital agenda by international commercial arbitrations
}

\author{
Ekaterina Kupchina* \\ RUDN University, 117198 Moscow, Russia
}

\begin{abstract}
It is almost impossible to astonish anyone in the era of global digitalization and the Internet of Things. Modern digital technologies and artificial intelligence have become an integral part of everyday life. Neural networks analyze information and photographs that we post on the Internet, and artificial intelligence programs have learned to reproduce and create intellectual property objects independently. Undoubtedly, this situation contributes to an increase in cross-border disputes, and arbitration procedures are becoming more attractive for participants. The development of the information and communication environment significantly impacts the means and methods used by arbitrators and parties in arbitration. Online arbitration, video conferencing, electronic databases, systems for analyzing court and arbitration practice, and templates and document designers are used daily. Due to the wide distribution and diversity of digital tools, this area, like nothing else, needs effective regulation. In this regard, the author of this article concludes on the possibility of conducting an analysis on the implementation of the digital agenda by international commercial arbitration tribunals, identifying the main trends in the development of the arbitration procedure, and improving the legislation in this area.
\end{abstract}

\section{Introduction}

The world we live in is changing rapidly. Thanks to modern digital technologies and ubiquitous access to the Internet, global economic ties evolve and improve. From year to year, the number of cross-border transactions is soaring, and, subsequently, the number of disputes arising from them is increasing. When resolving international disputes, including those related to the circulation of intellectual property objects and the transfer of exclusive rights of intellectual activity, arbitration has long become a platform for fast and efficient proceedings. The basis for any arbitration is the principle of party autonomy. Based on this principle, most of the procedural issues for holding hearings are resolved: evidence gathering and provision, hearings of witnesses, and others [1]. In this regard, international commercial arbitration is an ideal platform for implementing most states' digital agenda and a policy to improve the arbitration system. There is no doubt that the parties to the proceedings are using digital technologies for the sake of the technologies themselves. Digitalization only contributes to the improvement and optimization of existing processes and mechanisms. For example, in connection with the expansion of access to the Internet, there has been a transition

\footnotetext{
*Corresponding author: belousova_ev@pfur.ru
} 
from filing applications and documents in hard copy, first to email, and then to cloud services and unique platforms that allow parties to view and work with documents simultaneously.

\section{Methodology}

A multi-criteria and comprehensive study of the possibility and feasibility of using information and communication technologies in considering disputes by international arbitration tribunals is the basis for effective relations between participants in cross-border relations. The study's methodology is based on research and theoretical approaches to studying arbitration regulations and some national sources and other regulations. The author provides examples of the most commonly used digital methods and tools to settle disputes through arbitration based on the data analysis. This study is based on the opinions of leading scholars and experts in the studied and related fields, since the correct theoretical understanding of the issues posed in this study makes it possible to form an idea of the main features and potential problems of the information implementation and communication technologies in arbitration.

\subsection{Information and communication technologies as the basis for the development of modern economic and socio-cultural relations}

The global digital revolution is making changes in all domains of human relationships. Digital technologies are among the most dynamically developing areas [2]. However, the consequences of information and communication technologies introduction impact public institutions' interaction at the national and international levels. Digitalization brings new opportunities for businesses, including small and medium-sized businesses, and the state, posing new challenges. Most of the modern world's trading operations are carried out using electronic communication means, which has a positive impact on the development of most sectors of the world economy. The digital transformation of society contributes to the formation of an information space, taking into account the needs of citizens and society in obtaining high-quality and reliable information, as well as the formation of a technological basis for the social and economic spheres [3].

\subsection{Information and communication technologies as a mechanism to improve the efficiency of arbitration proceedings}

While analyzing modern digitalization processes, we need to pay special attention to the consideration of international commercial disputes. Filing a case to arbitration rests on the principle of autonomy of the will of the parties. It enables the parties to resort to a wide range of means and drivers, including digital tools, to ensure the most effective litigation. Besides, the organization of communication between the parties to the dispute is an equally important criterion. In this regard, digital tools have opened new opportunities for parties to organize interaction, which greatly simplified most arbitration procedures.

However, the widespread use of digital technologies in arbitration has made it more vulnerable to cyberattacks. The information security system is a set of corporate rules standards, including procedures to ensure this information security. These elements, as a rule, are formed based on an audit of the company's information system and an analysis of existing security risks following the requirements of regulatory documents and provisions of standards in information security [4]. 


\section{Results}

Participants in cross-border relations traditionally view arbitration procedures as an alternative to litigation in courts. This procedure is most attractive due to a significant reduction in the costs of hearings. This figure can be further reduced through digital tools, allowing parties to avoid the cost of travel expenses for representatives and sending correspondence in traditional ways.

Confidentiality is another essential principle of arbitration. Having become widespread in arbitration, information and communication technologies can be considered a factor that has a positive impact on the development and promotion of arbitration procedures and contributes to an increase in the risk of disclosing confidential information.

The first and undoubtedly positive point is that digital tools allow you to transfer and store information faster and more securely using blockchain technology [5]. The use of distributed ledger technology excludes the possibility of unscrupulous persons entering the stored information and making any changes.

The second criterion is the fact that advances in technology are opening up more opportunities for cyber attacks. The parties continue to use insecure communication channels such as email, instant messengers, unencrypted cloud services, and other ways to exchange documents. To minimize these risks, the International Council for Commercial Arbitration (ICCA), the New York City Bar Association, and the International Institute for Conflict Prevention and Resolution (CPR) developed the Information Security Protocol (ICCA-NYC BAR-CPR Cybersecurity Protocol for International Arbitration) [6] as well as the TransCEND platform. The above Protocols allow arbitrators, parties, and advisors to store securely, transfer and edit confidential documents from anywhere in the world. The main recommendations contained in these documents and guides include:

- using password-protected platforms that provide unique, automatically generated meeting IDs for each virtual hearing;

- using only secure internet connections;

- appointing the organizer to supervise the entry of participants and providing the organizer with a list of participants before the hearing;

- avoiding the use of information that would reveal the identity of the parties in the online hearing;

- being aware of the terms of service that apply to the platform's recording functions, and disabling or formalizing the conditions under which sessions are recorded;

- using secure file sharing platforms or cloud storage (with a password-protected link to a file that needs to be uploaded within a few days, after which the cloud record will be deleted);

- prohibiting any audio, video, or screen capture of the hearing other than the official recording [7].

\section{Discussion}

\subsection{Application of digital technologies by international arbitration tribunals}

\subsubsection{American Arbitration Association (AAA)}

By now, digitalization has affected even the most remote corners of our planet. The interaction at the interstate level is actively developing to provide comprehensive assistance and support to developing countries to introduce and promote information and communication technologies in all spheres of economic and social relations. In this regard, 
the USA can be distinguished among the most progressive countries. The widespread use of digital technology in the USA arbitration institutions began at the end of the 20th century. An unprecedented case was the 1996 fully online hearing on the domain name dispute by the "Virtual Magistrate," sponsored by the American Arbitration Association. Besides, the American Arbitration Association (AAA) is one of the first arbitration institutions to launch its own AAA WebFile online service [8]. Thanks to this platform's use, the parties could file complaints on the Internet, make payments, manage cases online, transmit and receive documents in electronic form, select arbitrators, and receive information about the proceedings' course and the status of the case. This interface is relatively easy to use, and even inexperienced users can apply it through this system. The complaint process begins with registering on the site and generating a user's password. It is followed by a choice of the procedure by which the dispute should be resolved: arbitration or mediation. The AAA's competence to resolve a specific dispute is resolved either by uploading an agreement containing the appropriate arbitration clause or directly by an agreement on the selection of AAA as an arbitration institution. The information about the claimant and respondent can be filled in automatically based on previously submitted applications. When applying, an administrative fee is required, which varies depending on the amount of the claim and the type of dispute. All payments, in this case, are only accepted by credit card. After filling in all the required information and paying the required fees, the user receives a confirmation number from AAA WebFile by email, and the claim itself is displayed in the online service in the "pending claims" section. The process of verifying the applicant's information takes no more than 2-3 days and, if the application is accepted, its status is also displayed in the personal account. All further information about the course of consideration of the dispute and incoming documents is found in the section "Information on the filed case."

In addition to this online filing procedure via AAA WebFile, the American Arbitration Association dispute resolution procedure uses AAA-ICDR video conferencing technology to enable parties to virtually and securely resolve their disputes from anywhere. As a rule, the Zoom platform is used for video conferencing. This hearing format provides a complete and equal opportunity for all parties to present evidence during the hearing.

\subsubsection{London International Commercial Arbitration}

Among the most important and prominent arbitration centers, the LCIA is the oldest arbitration institution. For more than 100 years of its existence, the regulations of this center have been repeatedly revised. The latest amendments to the LCIA Arbitration Rules were made on October 1, 2020 [9], which is an expected response to changes in the existing dispute resolution mechanisms. The amendments' primary purpose is to simplify the proceedings on incoming cases and detailed regulation of the issues of using information and communication technologies in arbitration. According to the updated Regulations, an application in hard copy can only be submitted in an exceptional case and upon receipt of written permission by the registrar to accept the application in this form. For all other cases, the priority of electronic appeal is established: from applying the dispute's decision.

To increase the efficiency and speed of the arbitration proceedings, significant changes were made to Art. 14 of the Rules, which gave the arbitration broader powers. In particular, Art. 14.5 and 14.6 establish the possibility of issuing any procedural order to expedite the procedure. This order may relate to limiting the scope of the content of written submissions (or rejecting them altogether), limiting written or oral testimony of witnesses, or even refusing to hearings. The rapid pace of digitalization of modern society and the experience of using digital tools during the COVID-19 pandemic are also reflected in the updated Rules of Arbitration. In particular, Art. 19.2 explicitly states that hearings may be held virtually by conference call, video conferencing, or other digital means of communication. 
Another significant change contained in Art. 26.2 of the Rules, provides for the possibility of signing an arbitral award with an electronic signature, subject to the existence of such agreement between the parties or the relevant instructions of the tribunal or the LCIA court. This innovation is beneficial for international commercial arbitration because the panel of arbitrators can often be composed of persons residing in different places worldwide. However, when signing an arbitral award with an electronic signature and the need for subsequent proper execution of the arbitration award, the requirements of the New York Convention on the Recognition and Enforcement of Foreign Arbitral Awards of 1958, as well as the requirements of the national legislation of the country where it is to be enforced, should be taken into account.

Special attention to the updated Rules is paid to information security and data protection. The LCIA's terms of reference and the arbitral tribunal include issuing information security or data protection instructions that are binding on the parties. The arbitration and the parties take information security measures at an early stage before the arbitration proceedings. Given the fundamental importance of data protection and cybersecurity in today's digital age, these amendments will significantly increase arbitration's credibility

\subsubsection{China International Economic and Trade Arbitration Commission (CIETAC)}

The practice of using information and communication technologies in the dispute settlement of the China International Economic and Trade Arbitration Commission (CIETAC) was introduced by special arbitration rules back in 2009. Much time has passed since that moment, taking into account the improvement of digital tools. The COVID-19 pandemic has left an imprint on all areas of human relationships, and, in this regard, in April 2020, CIETAC released Guidelines for Proactive and Proper Arbitration During the COVID-19 Pandemic [10]. This Guide significantly expands the range of procedural actions which use digital technologies. In particular, it calls for the full use of online case registration, electronic services, and CIETAC services, online hearings and regulates electronic signatures and electronic seals of arbitrators.

To take various approaches to online hearings, CIETAC has developed a dedicated platform for arbitration hearings and has also issued the CIETAC Trail (online hearings). This online platform opens up ample opportunities for arbitration participants. It provides such elements as verification of arbitration participants' identity, submission and display of electronic evidence, simultaneous online recording, affixing electronic signatures by scanning a QR code, and alike. So far, more than 200 cases have been heard through the online arbitration platform CIETAC.

CIETAC employs various approaches and modes of arbitration hearings, including online, offline, and hybrid hearings. This ability is mainly achieved by the presence of a network of sub-committees and cooperative institutions globally and the integration of headquarters and branches. Thanks to such broad capabilities, CIETAC achieves and satisfies the most complex and even individualized needs of arbitration hearings in various cases.

\subsubsection{Hong Kong International Arbitration Centre (HKIAC)}

The latest changes to the current version of the HKIAC Arbitration Rules were made in 2018. They have been substantially amended and supplemented with provisions regarding the need to take all necessary measures to ensure prompt and efficient arbitration proceedings. In addition to the Arbitration Rules, the Digital Litigation Guidelines were issued on May 14, 2020 [11]. To ensure the sustainable operation of all digital systems, HKIAC has partnered with leading IT specialists. Currently, arbitration participants have access to such tools as filing applications for arbitration in electronic form through an online platform, providing 
simultaneous and asynchronous translation online, video conferencing, cloud video conferencing, electronic provision of evidence. For the convenience of the arbitrators, as well as in order to optimize court procedures, including to minimize the risk of the spread of coronavirus infection, HKIAC has divided virtual hearings into three categories:

- face-to-face hearing with some features of distance hearings - arbitration participants are present in one place, but additional measures are needed to comply with the rules of social distancing;

- partial online hearing - one or more participants are present remotely;

- full online hearing - all participants and stakeholders participate remotely.

The most commonly used HKIAC arbitration format is mixed, which provides vast opportunities for participants and is most effective in resolving complex issues.

All virtual hearings, regardless of category, are secured with information security keys and passwords. The list of participants in the arbitration is negotiated and approved in advance.

\section{Conclusion}

The active implementation of information technologies in arbitration is an adequate response to the processes taking place within the digital revolution of the 21 st century. Experience with digital systems and tools has shown that arbitration can be more effective, even in extreme conditions. However, it does not mean that digital technologies are intended to completely replace existing systems and mechanisms in arbitration at this stage of its development. Despite the seeming simplicity of the technologies used, the integration of digital instruments into arbitration requires a clear and well-grounded approach to risk management based on the principle of "no harm." Software is designed by people who have their values and preferences [12]. In this regard, particular attention should be paid to digital literacy and essential skills development, both directly involved in arbitration proceedings and those operating the digital systems. In this regard, an important role is played by the construction of an effective information security system, which also acts as a crucial factor in ensuring confidentiality, data protection, and the possibility of strategic planning in arbitration. According to the above two criteria, it is necessary to ensure constant interaction between arbitrators and experts in information and communication technologies to achieve high-performance indicators. The active implementation of information and communication technologies reflects a conscious effort to adapt to modern realities [13]. In general, the digitalization of arbitration procedures is a welcome step, contributing to the efficiency and modernization of the existing toolkit, which allows the parties to more effectively solve the current problems related to travel restrictions and social distancing measures, which, in turn, should save the parties both time and the means.

This work has been financially supported by the Grant of the President of the Russian Federation №. HШ-2668-2020.6 «National-Cultural and Digital Trends in the Socio-Economic, Political and Legal Development of the Russian Federation in the 21 st Century».

\section{References}

1. S. Wachtel, Journal of the Digital Economy, 168 (2020)

2. E.P Rusakova, M.N. Dudin, O.F. Shakhov, M.S. Shakhova, Yu.S. Sizova, Int. J. of Recent Tech. and Engineering 8(2), 4436 (2019)

3. A.Yu Mamychev, D.A. Petrova, Ya.V.Gaivoronskaya, O.I. Miroshnichenko, Yu.I. Karimova, A.P. Alekseenko, V.N. Anikeeva, V.A. Nomokonov, D A. Sidorkin, N.R. Martyanov, A.P. Rabets, V.Yu. Shigvaleeva, M.A. Dorofeeva, V.P. Kuzmin, P.V. 
Kuzmin, A.M. Ivanov, D.I. Pobedash, E.I. Sinitsyna, M.D. Ostanin, S.N. Ovchinnikov at al. The world in the digital age: politics, law and economy of the XXI century. (pp. 15-18) LLC "Publishing Center RIOR" (2020)

4. E.E Frolova, T.A. Polyakova, M.N. Dudin, E.P. Rusakova, P.A. Kucherenko, J. of Advanced Res. in Law and Economics 9(1), 89 (2018)

5. E.V. Kupchina, EDULEARN20 Proceedings 12th International Conference on Education and New Learning Technologies, (pp 1287-1291). IATED (2020).

6. International Council for Commercial Arbitration. Cybersecurity Protocol for International Arbitration. Retrieved March 20, 2021, from https://www.arbitrationicca.org/

7. E. V. Kupchina, Legal Concept 19(2), 129 (2020)

8. American Arbitration Association. AAA WebFile and Panelist eCenter. Retrieved March 15, 2021, from https://www.adr.org/

9. London International Commercial Arbitration. LCIA Arbitration Rules. Retrieved March 18, 2021 from https://www.lcia.org/

10. China International Economic and Trade Arbitration Commission. CIETAC Virtual Hearing Statement. Retrieved March 10, 2021 from http://www.cietac.org/?l=en

11. Hong Kong International Arbitration Centre. Guidelines for Virtual Hearings. Retrieved March 12, 2021 from https://www.hkiac.org/

12. A.O. Inshakova, E.E. Frolova, M.V. Galkina, E.P. Rusakova, Int. J. of Sociology and Social Policy, 1 2020)

13. E.P. Ermakova, N.V. Ivanovskaya, S.Sh. Shakirov, 6th International Conference on Education and Social Sciences. Abstracts \& Proceedings. (OCERINT, 2019) 